\title{
Origen de los Changos. Análisis de ADNmt antiguo sugiere descendencia de pescadores de la cultura Chinchorro (7.900 - 4.000 A.P.)
} FRANCISCO ROTHHAMMER ${ }^{1,2, \mathrm{a}}$, MAURICIO MORAGA
CALOGERO M. SANTORO
,, BERNARDO T. ARRIAZA

\section{Origins of Changos. Mitochondrial DNA analysis suggests Chinchorro culture fishermen ancestry}

Sophisticated molecular genetics techniques allow the typification and posterior comparison of antique haplogroups and mitochondrial DNA sequences from prehistoric groups with contemporary populations. This adds a chronological dimension to these studies and contributes to have a better knowledge of the genetic composition of the Chilean population. This articles gives scientific support, using molecular methodology, to the alleged biological links that joined the descendants of proto historic Chango fishermen from Paposo cove, a place located 15 kilometers north of Taltal, with prehistoric fishermen from Chinchorro culture, that developed in Northern Chile and Southern Peru between 7900 and 4000 A.C.

(Rev Med Chile 2010; 138: 251-256).

Key words: DNA, mitochondrial; Genetics, population; Indians, South American.
${ }^{1}$ Centro de Alta Investigación, Universidad de Tarapacá. Arica, Chile.

${ }^{2}$ Programa de Genética Humana, Instituto de Ciencias Biomédicas (ICBM), Facultad de Medicina, Universidad de Chile. Santiago de Chile.

${ }^{a}$ Doctor en Ciencias (Genética) ${ }^{b}$ Doctor en Ciencias (Bioquímica)

'Doctor en Ciencias (Arqueología)

${ }^{\mathrm{d}}$ Doctor en Ciencias (Bioantropología)

Recibido el 20 de octubre de 2009, aceptado el 25 de noviembre de 2009. Artículo preparado por invitación de los editores.

Correspondencia a: Dr. Francisco Rothhammer. Programa de Genética Humana. Instituto de Ciencias Biomédicas, Facultad de Medicina, Universidad de Chile. Av. Independencia 1027, Casilla 70061, Santiago 7, Chile. E-mail: frothham@med.uchile.cl
S i bien el análisis de la composición genética de las poblaciones chilenas es relevante en el área disciplinaria de la antropología, también lo es en biomedicina. En efecto, al utilizar diseños metodológicos que involucren la comparación de casos y controles, es indispensable que ambos grupos sean genéticamente comparables. No basta que casos y controles pertenezcan a nuestra población general, debido al alto grado de heterogeneidad genética que ésta presenta. Recordemos que en Chile existen marcadas diferencias en los porcentajes de mezcla indígena entre diferentes zonas geográficas y, dentro de los límites de éstas, entre estratos socioeconómicos. Cabe agregar que las diferencias genéticas, que a su vez existen entre las etnias originarias, contribuyen a que esta heterogeneidad sea aun más relevante ${ }^{1}$.

La disponibilidad actual de sofisticadas técni- cas de biología molecular, permite extender los estudios genéticos a las poblaciones prehistóricas chilenas. Es ahora posible realizar comparaciones entre grupos prehistóricos y representantes actuales de etnias originarias, permitiendo establecer sus orígenes geográficos y relaciones de parentesco y lograr de esta forma un mayor conocimiento de nuestra geografía génica. En este artículo de revisión efectuamos uno de los primeros aportes al estudio comparativo de grupos prehistóricos y étnicos actuales, estableciendo la relación genética entre individuos pertenecientes a la Cultura Chinchorro, que se desarrolló en las costas del Norte de Chile y el Sur de Perú entre 7900 y 4000 A.P. y descendientes de changos. Incluimos además en el análisis a diferentes representantes de pueblos originarios del norte, centro y sur de Chile, con fines comparativos. 
Origen de los Changos. Análisis de ADNmt sugiere descendencia de la cultura Chinchorro - F. Rothhammer et al

Tabla 1. Frecuencia relativa de haplogrupos mitocondriales en etnias originarias chilenas

\begin{tabular}{|lrrrrrc|}
\hline Población & n & A & B & C & D & H \\
\hline Chinchorro Arcaico Medio & 4 & 0,250 & 0,500 & 0,000 & 0,250 & $0,833 \pm 0,222$ \\
\hline Chinchorro Arcaico Tardío & 14 & 0,357 & 0,357 & 0,071 & 0,215 & $0,747 \pm 0,066$ \\
\hline Chinchorro Total & 18 & 0,333 & 0,389 & 0,056 & 0,222 & $0,726 \pm 0,055$ \\
Changos & 37 & 0,027 & 0,514 & 0,162 & 0,297 & $0,638 \pm 0,052$ \\
Aymara & 292 & 0,070 & 0,640 & 0,150 & 0,140 & $0,509 \pm 0,060$ \\
Atacameños & 74 & 0,110 & 0,680 & 0,160 & 0,050 & $0,545 \pm 0,029$ \\
Huilliche & 80 & 0,040 & 0,290 & 0,185 & 0,485 & $0,651 \pm 0,032$ \\
Pehuenche & 205 & 0,025 & 0,095 & 0,390 & 0,490 & $0,599 \pm 0,018$ \\
Mapuche & 111 & 0,000 & 0,070 & 0,440 & 0,490 & $0,568 \pm 0,021$ \\
Yagan & 21 & 0,000 & 0,000 & 0,480 & 0,520 & $0,524 \pm 0,036$ \\
\hline
\end{tabular}

La Cultura Chinchorro fue descubierta en 1917 por el arqueólogo alemán Max Uhle, en las cercanías de playa Chinchorro en Arica ${ }^{2,3}$. Éste se impresionó por el elaborado tratamiento que los integrantes de esta cultura habían dado a los cuerpos de sus muertos. En efecto, Uhle distinguió varios tipos de momificación artificial practicada por estos grupos, que posteriormente, mediante fechados radiocarbónicos, resultó ser más antigua que aquella realizada por los egipcios. En líneas generales, las sociedades de pescadores que habitaban el norte de Chile durante el siglo XVI provenían de una tradición cultural que se remontaba a varios milenios antes de Cristo, según revela el testimonio de los cronistas españoles ${ }^{4,5}$, existiendo cierto consenso entre los etnohistoriadores y arqueólogos en que los changos podrían haber sido descendientes de los grupos chinchorro.

No obstante, el problema de identidad étnica es complejo, sobre todo en épocas tardías. Los nombres de "camanchacos" (de "neblina", en aymara), "camanchangos" o simplemente "changos", fueron denominaciones genéricas utilizadas por los españoles para designar a los pescadores del área costera meridional de Perú y septentrional de Chile, desde Camaná hasta Coquimbo. Los españoles también utilizaron los nombres de "uros independientes" o "uros de la costa" para llamar a los changos. Sin duda, sorprende la presencia de los uros altiplánicos del Lago Titicaca en la costa, aunque ambos grupos se dedicaban a la misma actividad económica: la pesca. Además, en la costa habitaban grupos "yunga" o "yunka", lo que confunde más aun el panorama étnico desde los siglos XVI hasta el XVIII ${ }^{6-8}$.

Por otra parte, Boman a comienzos del siglo XX propuso la existencia de una relación histórica entre los grupos costeros uros descritos por Lozano Machuca en 1581 y los pescadores descritos durante los siglos XVI y XVII por los expedicionarios y cronistas Frezier, D'Orbigni, Philippi y Bollaert y estimó que estos changos o uros de la costa serían "los últimos vestigios de un antiguo pueblo que habitó la región antes de los yuncas, los quichuas y los aymaras"

Bibar $^{8}$ señala que durante el siglo XVI los grupos prehistóricos del litoral se dedicaban a la pesca, actividad para la que utilizaban embarcaciones o balsas manufacturadas con cueros de lobos marinos inflados. Sobre estos flotadores sujetaban una plataforma de madera, que permitía transportar de uno a cuatro navegantes. Este tipo de embarcación era usada preferentemente para la pesca costera, para la cual utilizaban un arpón de hueso o en algunas ocasiones de cobre, amarrado a un cordel de cuero.

Los grupos costeros eran pescadores y recolectores, especialmente de mariscos y huevos de aves guaneras. Se agrupaban en pequeñas familias y probablemente rendían culto a sus muertos, a los que enterraban junto a sus herramientas de trabajo. También tenían relaciones comerciales con los asentamientos pre y post incaicos del interior, como los oasis de Pica y Guatacondo. Los conquistadores españoles quedaron impresionados con su modo de vida primitivo, pero fundamen- 
talmente por su aspecto. Debido a su condición de pescadores, tenían el pelo decolorado y su piel rojiza, producto del contacto con sangre de lobo marino, que utilizaban para calmar la sed como complemento, ante la escasez de agua. De acuerdo al testimonio de Fray Reginaldo de Lizárraga ${ }^{10}$.

...en este trecho de tierra hay algunas caletillas con poca agua salobre, donde se han recogido y huido algunos indios pescadores, pobres y casi desnudos; los vestidos son de pieles de lobos marinos, y en muchas partes desta costa beben sangre destos lobos a falta de agua; no alcanzan un grano de maíz, no lo tienen; su comida sola es pescado y marisco. Llaman a estos indios Camanchacas, porque los rostros y cueros de sus cuerpos se les han vuelto como una costra colorada, durísimos; dicen les previene de la sangre que beben de los lobos marinos, y por esta color son conocidísimos.

Los grupos costeros conocían el empleo de la sal para hacer charqui de pescado o bolsas de pescado salado, que eran parte de su moneda de trueque para conseguir frutas y licores de otros grupos étnicos que habitaban los valles durante ese período. Estos poblados nómadas, que recorrían el litoral en busca de sustento y vivían provisionalmente en tolderías de cueros de lobos o focas, fabricaban además redes de algodón para la pesca. Agregamos como curiosidad que la información etnohistórica disponible revela que los grupos changos que habitaban la desembocadura del río Loa en 1866 se apellidaban Sinquilla, Llombeque, Seyama, Vilayo, Casana, Capollo, Cissama, Llapa, Huaca y Sullo, entre otros. Para comienzos del siglo XX se señala la existencia de unas pocas familias que habitaban algunos lugares aislados de la costa y que habían ya dejado atrás los rasgos característicos de modo de vida descritos por expedicionarios y cronistas $^{5-7}$. La etnia se extinguió alrededor del año 1890, estando sus últimos asentamientos en Caleta Paposo, al norte de Tal Tal y La Quiaca en Tacna, Perú ${ }^{5,6}$.

En el presente artículo intentaremos verificar la creencia que los pescadores changos fueron los últimos herederos de la Cultura Chinchorro ${ }^{3-6}$. Para cumplir nuestro propósito, utilizaremos metodología molecular, específicamente ADNmt (ácido desorribonucleico mitocondrial). Debido a que éste se transmite exclusivamente por vía materna, se conservan los linajes durante muchas generaciones, posibilitando la estimación de relaciones de parentesco remotas entre pobla- ciones extintas y actuales. En la actualidad viven en Caleta Paposo (II Región; 250.03' S, 70²7’O), distante 51 kilómetros al norte del puerto de Tal Tal, descendientes de changos, que fueron objeto de un análisis genético molecular previo por parte de nuestro grupo ${ }^{11}$. Se incluyeron 37 individuos no relacionados, portadores de los haplogrupos amerindios A, B, C y D, que en conjunto representaban aproximadamente el $13 \%$ de la población de la caleta.

Los grupos chichorro fueron estudiados por nosotros en dos momentos importantes de su larga historia, el período arcaico medio (7.000 A.P.) y el arcaico tardío (4.000 A.P $)^{12}$. Los cuerpos fueron exhumados, respectivamente, en la desembocadura del río Camarones, en 1989, por Schiapacasse y Niemeyer ${ }^{13}$ y en las faldas del Morro de Arica por los arqueólogos Vivien Standen y Guillermo Focacci, en 1983, a raíz de trabajos de excavación realizados por empleados municipales.

\section{Tipificación de haplogrupos de ADNmt}

Aproximadamente $1 \mathrm{~g}$ de hueso fragmentado fue descontaminado a través de sucesivos lavados con hipoclorito de sodio y agua bi-destilada estéril. Posteriormente, el hueso fue descalcificado con EDTA, digerido con proteinasa $\mathrm{K}$ y el ADN extraído con fenol: cloroformo: alcohol isoamílico, seguido de cloroformo: alcohol isoamílico. Luego el ADN fue precipitado con isopropanol y acetato de amonio, lavado con etanol al 75\% y resuspendido en agua bi-destilada estéril. Finalmente, el ADN fue purificado y concentrado utilizando "Wizard SV Gel and PCR Clean-Up System" (Promega), según las indicaciones del proveedor. Todos los procedimientos se realizaron en un laboratorio dedicado exclusivamente a la extracción de ADN antiguo, que cuenta con presión positiva de aire calidad HEPA, luz UV germicida y todas las medidas que garantizan minimizar los riesgos de contaminación. Todas las extracciones se realizaron en duplicado, incluyendo controles de extracción.

La amplificación de las regiones de ADNmt que contienen los polimorfismos que definen los haplogrupos amerindios se realizó mediante la técnica de PCR (Polymerase Chain Reaction), utilizando las parejas de oligonucleótidos partidores y el programa de PCR descritos por Moraga y colaboradores ${ }^{12}$. Los haplogrupos A, C y D fueron 
analizados por digestión con endonucleasas de restricción específicas: Hae III para el haplogrupo A; Hinc II para el haplogrupo C y Alu I para el haplogrupo D. La determinación del haplogrupo B se realizó directamente, a través de la observación de los productos de amplificación obtenidos. Tanto los resultados de las digestiones para los haplogrupos A, C y D como el producto de PCR que define al haplogrupo $\mathrm{B}$ fueron analizados por electroforesis en gel de agarosa 2,5\% (TAE 1X) teñido con bromuro de etidio.

\section{Procedimientos y resultados estadísticos}

La afinidad genética entre las poblaciones fue evaluada a partir de las frecuencias de haplogrupos, calculando las distancias genéticas según Rogers ${ }^{14} \mathrm{y} \mathrm{Nei}^{15}$ incluidas en el programa Biosys $1.0^{16}$. Además, se calculó el estadígrafo $\mathrm{Fst}^{17}$ utilizando el programa Arlequin 3.1 $1^{18}$. La matriz de distancias fue representada gráficamente mediante un dendrograma construido a través del método neighbor-joining $(\mathrm{NJ})^{19}$, utilizando el programa MEGA 4.1 ${ }^{20}$. La diversidad genética de cada población $(\mathrm{H})$ fue calculada según $\mathrm{Ne}^{15}$ con el programa Arlequin $3.11^{18}$. Finalmente, se realizó un análisis de varianza molecular $\mathrm{AMOVA}^{21}$ para estimar el grado de subdivisión poblacional, utilizando el programa Arlequín 3.11 ${ }^{18}$.

Las frecuencias relativas de los haplogrupos A, B, C y D para los individuos chinchorro, los descendientes de changos y para varias etnias originarias del norte, centro y sur de Chile, se consignan en la Tabla 1. Las distancias genéticas obtenidas a partir de la frecuencia de haplogrupos de ADNmt (distancia de Rogers modificada) ${ }^{14}$ in- dicaron que los cuerpos momificados de la Cultura Chinchorro (sumando las muestras pertenecientes al arcaico medio y tardío) exhiben la menor distancia genética con los changos $(0,178)$, seguida por las distancias con aymaras $(0,193)$ y atacameños $(0,211)$. A su vez, los changos mostraron estar genéticamente cercanos a los aymara, atacameños y chinchorros. Idénticos resultados se obtuvieron con otros métodos, tales como el de $\mathrm{Nei}^{15}$ y el de valores Fst $^{17}$ (Tabla 2).

El análisis de Fst, detectó diferencias significativas entre pares de poblaciones, con excepción de las que se mencionan a continuación: chinchorrochango $(0,09009 \pm 0,0271)$, chango-aymara $(0,07207 \pm 0,0227)$ y aymara-atacameño $(0,27928$ $\pm 0,0417)$ para el grupo del norte y mapuchepehuenche $(0,73874 \pm 0,0354)$, mapuche-yagan $(0,83784 \pm 0,0361)$ y pehuenche-yagan $(0,54054$ $\pm 0,0525)$ para el grupo del sur.

Basados en la matriz de distancias genéticas (Tabla 2) se construyó un dendrograma que ilustra la relación genética entre los grupos estudiados (Figura 1). La misma topología se obtuvo al construir un dendrograma con base en la distancia de $\mathrm{Nei}^{15}$ o los valores de Fst ${ }^{17}$.

Básicamente, se distinguen dos grupos de poblaciones: por una parte los grupos chinchorro junto con changos, atacameños y aymaras y por otra los grupos huilliches, pehuenches, mapuche y yaganes. Llama la atención que, entre los grupos étnicos meridionales, los huilliches, pueblo que vive cerca de la costa, son los más cercanos genéticamente a los grupos del litoral norte, insinuando un contacto prehistórico costero.

El análisis AMOVA, que fue realizado considerando dos grupos (norte y sur) de acuerdo a lo

Tabla 2. Distancias genéticas entre etnias originarias chilenas

\begin{tabular}{|lcccccc|}
\hline & Chinchorro & Chango & Aymara & Atacameño & Huilliche & Pehuenche Mapuche \\
Chango & 0,178 & & & & & \\
Aymara & 0,193 & 0,103 & & & & \\
Atacameño & 0,211 & 0,156 & 0,055 & & & \\
Huilliche & 0,215 & 0,148 & 0,249 & 0,298 & & 0,140 \\
Pehuenche & 0,302 & 0,257 & 0,346 & 0,387 & 0,168 & 0,031 \\
Mapuche & 0,329 & 0,279 & 0,366 & 0,406 & 0,205 & 0,067 \\
\hline Yagan & 0,364 & 0,322 & 0,409 & 0,448 & 0,043 \\
\hline
\end{tabular}

Distancia de Rogers modificada ${ }^{12}$ 


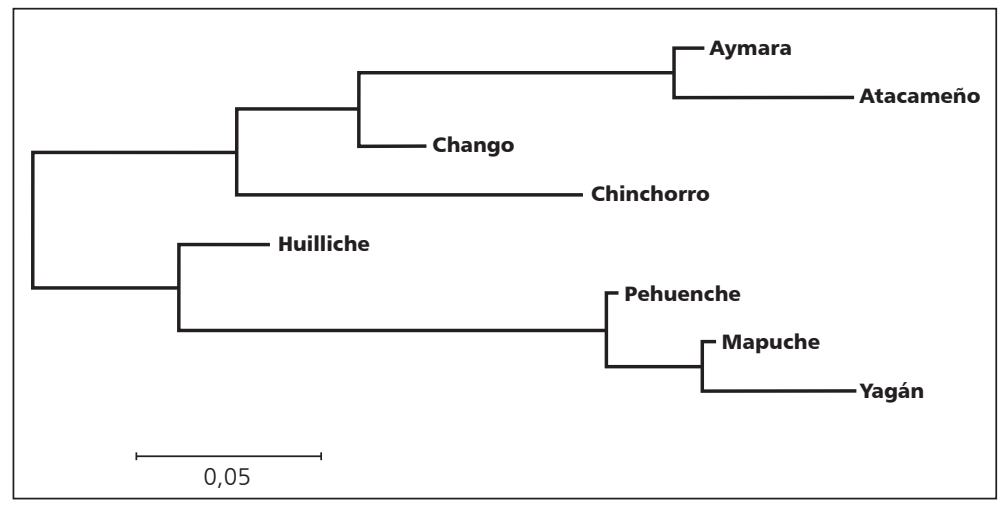

Figura 1. Dendrograma neighborjoining (NJ) basado en la matriz de distancias de la Tabla 2. sugerido por los resultados ya expuestos, demostró que $72,14 \%$ de la varianza total corresponde a diferencias intrapoblacionales, mientras las diferencias intergrupales explicaron $25,74 \%$ y las diferencias entre poblaciones dentro de un grupo representaron el 2,13\% restante.

\section{Conclusiones}

Si centramos nuestra atención en los grupos chinchorro (7900 A.P.- 4000 A.P.) descubrimos que la población genéticamente más próxima a éstos son los changos. Nótese que hemos considerado solamente los haplogrupos indígenas de Caleta Paposo, eliminando de esta manera el aporte genético debido a mezcla no indígena $\mathrm{y}$, en consecuencia, posibles distorsiones causadas por este factor. Cabe hacer notar que en el trabajo previo realizado en Caleta Paposo, encontramos que el $93 \%$ de los individuos examinados eran portadores de haplogrupos de ADNmt indígenas ${ }^{11}$.

Si bien los resultados sugieren que los antiguos grupos chinchorro dieron origen a los changos, resulta pertinente preguntarse por qué los changos de Caleta Paposo también eran genéticamente próximos a los grupos aymaras y atacameños, históricamente más recientes. En este contexto debemos mencionar que grupos étnicos tales como lupacas, coles, uros, atacameños y puquinas habitaban durante el siglo XVI en la cabecera de los valles costeros del norte de Chile y sur de Perú como consecuencia de la expansión Tiwanaco del siglo IX, que se desplazó por todo el Colesuyo ${ }^{22,23}$. La denominación de "uros de la costa" con que los españoles denominaban a los changos también podría deberse a este hecho.
El análisis de indicadores culturales para los changos habría indicado que esta denominación más bien estaba relacionada con una forma de vida y, por consiguiente, podría ser atribuible a cualquier grupo de pescadores prehistóricos costeros de la región ${ }^{23}$. Estos pescadores supuestamente habrían constituido una comunidad multiétnica, en particular después del dominio inca. Sin duda, como ha sugerido Herrera, un aporte significativo para dilucidar el problema de la identificación étnica de los changos, en especial para determinar si en el litoral norte de Chile existió un grupo costero con características genéticas propias, era realizar un estudio de las poblaciones de pescadores prehistóricos y luego un análisis comparativo de la variación genética mitocondrial de los grupos estudiados ${ }^{23}$.

Si comparamos la variabilidad haplotípica (una medida directa de la variación genética mitocondrial) de los changos $(0,64)$ con aquella observada para otras etnias originarias, encontramos que ésta es semejante a la de los atacameños, aymaras, huilliche, pehuenches, mapuches y yaganes (Tabla 2). En consecuencia, los changos, a pesar de haber sido supuestamente una población multiétnica en el siglo XVI, no se destacan por presentar una alta variabilidad genética mitocondrial. Concluimos que la multietnicidad de los changos, basada en el análisis etnohistórico, no se refleja genéticamente, indicando que ésta, si es que realmente existió, era más bien un reflejo de su heterogeneidad cultural.

Agradecimientos: Los autores agradecen el apoyo económico de los Proyectos Fondecyt No 1095006 y Convenio de Desempeño UTA/Mecesup-2. 


\section{Referencias}

1. Rothhammer F, Cruz-Coke R. Curso Básico de Genética Humana. Ediciones de la Universidad de Chile. 1983. Segunda edición corregida.

2. Uhle M. Los Aborígenes de Arica. Publicaciones del Museo de Etnología y Antropología de Chile. Santiago, 1917; 1: 151-76.

3. Arriaza B. Beyond Death. The Chinchorro Mummies of Ancient Chile. Smithonian Institution Press Washington DC 1995.

4. Hidalgo J. Culturas Protohistóricas del Norte de Chile. Editorial Universitaria 1972.

5. Bittmann B. Notas sobre las poblaciones de la costa norte grande de Chile. En Aproximaciones a la Etnohistoria del Norte de Chile y Tierras Adyacentes. Editado por JM Casassas 1977; pp. 56-115. Universidad del Norte, Antofagasta.

6. Bittmann B. El proyecto Cobija: Investigaciones Antropológicas en el Desierto de Atacama (Chile). XLIV Congreso Internacional de Americanistas. Publicaciones de la Universidad del Norte 1984.

7. Llagostera A. Caza y Pesca Marítima (9000 a 1000 a.C.) En Culturas de Chile, prehistoria. J Hidalgo et al (eds) 1989. pp 57-79 Santiago.

8. Bibar G. Crónica y Relación Copiosa y Verdadera de los Reinos de Chile 1558. Santiago, 1966.

9. Boman E. Antigüedades de la Región Andina de la República de Argentina y del Desierto de Atacama. Tomos I y II. 1908-1991. Universidad Nacional de Jujuy, Jujuy.

10. Lizárraga R. Descripción colonial (libro primero). 15451615. Lima.

11. Henríquez H, Moraga M, Llop E, Rothhammer F. Caracterización Genético Molecular de Caleta Paposo, Último Reducto Chango en Chile. Rev Med Chile 2004; 132: 663-72.

12. Moraga M, Santoro C, Standen V, Carvallo P, Rothhammer F. Microevolution in Prehistoric Andean Populations: Chronologic mtDNA variation in the Desert
Valleys of northern Chile. Amer J Phys Anthropol 2005; 127: $170-81$

13. Schiappacasse V, Niemeyer H. Avances y sugerencias para el conocimiento de la prehistoria tardía de la desembocadura del valle de Camarones (Región Tarapacá). Chungará 1989; 22: 63-84.

14. Wright S. Evolution and the Genetics of Populations. Variability Within and Among Natural Populations. Vol. 4; 1978. University of Chicago Press, Chicago.

15. Nei M. Estimation of Average Heterozygosity and Genetic Distance from a Small Number of Individuals. Genetics 978; 89: 583-90.

16. Swofford D, Selander R. Biosys: A fortran program for the comprehensive analysis of electrophoretic data in population genetics and systematics. J Hered 1981; 72: 281-7.

17. Wright $\mathrm{S}$. The genetical structure of populations. Ann Eugen 1951; 15: 323-54.

18. Excoffier L, Laval G, Schneider S. Arlequin (version 3.0): An integrated software package for population genetics data analysis. Evol Bioinform Online 2005; 1: 47-50.

19. Saitou N, Nei M. The neighbor-joining method: a new method for reconstructing phylogenetic trees. Mol Biol Evol 1987; 4: 406-25.

20. Tamura K, Dudley J, Nei M, Kumar S. MEGA4: Molecular Evolutionary Genetics Analysis (MEGA) software version 4.0. Molecular Biology and Evolution 2007; 24: 1596-9.

21. Excoffier L, Smouse PE, Quattro JM. Analysis of molecular variance inferred from metric distances among DNA haplotypes: application to human mitochondrial DNA restriction data. Genetics 1992; 131: 479-9.

22. Uhle M. Fundamentos étnicos y arqueología de Arica y Tacna. $2^{\text {nd }}$ Ed. Quito Ecuador Sociedad Ecuatoriana de Estudios Históricos 1922.

23. Herrera JA. Indicadores culturales para los llamados changos. Ethnos 1 Universidad de Chile. Facultad de Ciencias Sociales 1997. 